\title{
Preoperative hyaluronic acid injection modulates postoperative functional outcome in patients undergoing arthroscopic rotator cuff repair
}

\author{
Yosuke Nakamura', Masafumi Gotoh ${ }^{2 *}$, Yasuhiro Mitsui ${ }^{2}$, Hidehiro Nakamura', Hiroki Ohzono',
}

Takahiro Okawa ${ }^{2}$ and Naoto Shiba ${ }^{1}$

\begin{abstract}
Background: Arthroscopic rotator cuff repair (ARCR) generally yields acceptable clinical results. Hyaluronic acid (HA), a high-molecular-weight polysaccharide, is present in the extracellular matrix of soft connective tissue and synovial fluid, and its injection is known to significantly improve pain and clinical outcomes after rotator cuff injury. Some studies have described the role of HA injections as conservative therapy for rotator cuff tears. Since the subacromial bursa is believed to be the main source of shoulder pain in rotator cuff tears, subacromial injection is frequently used before surgery; however, its relationship with the clinical outcome after surgery remains unclarified. Therefore, we aimed to examine effects of preoperative subacromial HA injection on postoperative clinical outcome in patients with ARCR.
\end{abstract}

Methods: Ninety-eight patients were divided into a HA injection group and a non-injection group. The functional outcome measured was the University of California, Los Angeles (UCLA) score. Univariate analysis was performed to obtain variables with $p$ values less than 0.1 ; we then used propensity score analysis, adjusting for pre- and postoperative confounding factors.

Results: The UCLA scores of all patients significantly improved 1 year postoperatively $(\mathrm{PO})(p<0.05)$. Subacromial HA injections were performed in patients with worse preoperative function. Univariate analysis showed significantly greater improvements in the injection group than in the non-injection group in terms of preoperative UCLA score, trauma, diabetes mellitus, UCLA score 3 months $\mathrm{PO}$, abduction strength 4 months $\mathrm{PO}$, and internal rotation (IR) strength 6 and 12 months PO. Propensity score analysis demonstrated that UCLA scores 3 months PO and IR strength 12 months $P O$ in the injection group were significantly greater than those in the non-injection group. There were no significant differences in postoperative re-tear rates between the groups. In sub-analysis of the injection group, propensity scores showed that concurrent use of local anesthetics did not affect the data, suggesting that HA was effective.

(Continued on next page)

\footnotetext{
* Correspondence: gomasa@med.kurume-u.ac.jp

${ }^{2}$ Department of Orthopedic Surgery, Kurume University Medical Center,

155-1 Kokubu-machi, Kurume, Fukuoka 839-0863, Japan

Full list of author information is available at the end of the article
}

(c) The Author(s). 2020 Open Access This article is licensed under a Creative Commons Attribution 4.0 International License, which permits use, sharing, adaptation, distribution and reproduction in any medium or format, as long as you give appropriate credit to the original author(s) and the source, provide a link to the Creative Commons licence, and indicate if changes were made. The images or other third party material in this article are included in the article's Creative Commons licence, unless indicated otherwise in a credit line to the material. If material is not included in the article's Creative Commons licence and your intended use is not permitted by statutory regulation or exceeds the permitted use, you will need to obtain permission directly from the copyright holder. To view a copy of this licence, visit http://creativecommons.org/licenses/by/4.0/ The Creative Commons Public Domain Dedication waiver (http://creativecommons.org/publicdomain/zero/1.0/) applies to the data made available in this article, unless otherwise stated in a credit line to the data. 
(Continued from previous page)

Conclusion: Subacromial injection was administered to patients with worse function before ARCR. Propensity score analysis successfully demonstrated that functional outcome after surgery was improved in patients who were administered this injection compared with patients who were not administered this injection before surgery.

Keywords: Rotator cuff tear, Arthroscopic rotator cuff repair, Hyaluronic acid, Subacromial injection, Functional outcome, Propensity score analysis

\section{Background}

Rotator cuff tears cause pain and impaired mobility of the shoulder in middle-aged and older patients. They are often treated by arthroscopic rotator cuff repair (ARCR) surgery. Rouhani et al. reported that preoperative treatment with oral COX-2 inhibitors improves pain in the early postoperative period, thus helping achieve good outcomes after ARCR [1]. However, a study by Inderhaug et al. of postoperative outcomes after 6-9 years found that preoperative nonsteroidal anti-inflammatory drug (NSAID) treatment was a factor that contributed to poor outcomes [2]. Donohue et al. reported that patients who received a steroid injection in the subacromial bursa (SAB) before undergoing ARCR had significantly better visual analog scale (VAS) scores, American shoulder and elbow surgeons (ASES) shoulder scores, and constant scores 1 year postoperatively (PO) than patients who did not receive these injections [3]. Another study found that steroid injections after ARCR reduced pain and improved range of motion 3 months $\mathrm{PO}$ compared with a control group [4]. Desai et al. reported a strong correlation between 2 or more steroid injections into the subacromial bursa before rotator cuff repair and the need for further surgery [5]. Cancienne et al. found that intraoperative steroid injections had a major effect on postoperative infection rates [2].

Hyaluronic acid (HA), a high-molecular-weight polysaccharide, is present in the extracellular matrix of soft connective tissue and synovial fluid, playing various physiological roles depending on the tissue. The value of HA's therapeutic effect is well attested, and there have been no reports of adverse events caused by HA injection. Lim et al. compared the efficacy of steroid injections with that of HA injections for arthritis of the shoulder and found that both brought about significant improvement, with no significant difference between the 2 [6]. Shibata et al. evaluated the use of HA and steroid injections for rotator cuff tears and found that pain and the University of California, Los Angeles (UCLA) scores improved significantly after treatment with either, compared with scores before treatment [7]. In a systematic review, Osti et al. found that intra-articular HA injections significantly improved pain and clinical outcomes after rotator cuff injury [8]. However, although some studies have described the role of HA injections as a conservative therapy for rotator cuff tears, few have evaluated its postoperative effect. We therefore treated rotator cuff tear patients with HA injections before ARCR and investigated its postoperative effects.

\section{Methods}

This retrospective study was approved by the institutional review board of the university where this study was conducted (no. 18136). Due to the retrospective nature of the study, the requirement of patient consent was waived.

\section{Subjects}

A total of 205 patients underwent ARCR at our institution between January 2014 and December 2016. The inclusion criteria required that patients (1) underwent ARCR and (2) complete a 1 year follow-up PO. The exclusion criteria included patients who (1) had systemic disease, (2) had fractures around the shoulder, and (3) underwent preoperative injections with agents other than HA (e.g., steroids). Finally, 98 patients with an average age of $63.5 \pm 9.1$ years were included. Depending on whether subacromial injection was given before surgery, patients were divided into 2 groups as follows: the injection group (58 patients, 23 patients with HA only, and 35 patients with HA + local anesthetics) and the noninjection group (40 patients).

Injections were given $<5$ times in 25 patients and $\geq 5$ times in 33 patients; of the 58 patients who received injections, 25 received them in our hospital and 33 at other hospitals. Members of both groups received NSAID therapy (41 patients in the injection group and 30 in the non-injection group) and physiotherapy (58 patients in the injection group and 40 in the non-injection group). The mean duration of preoperative treatment was 8.4 months in the injection group and 8.9 months in the non-injection group.

\section{Surgical technique and postoperative regimen}

Patients underwent ARCR in the beach-chair position under general anesthesia along with an interscalene block. The torn cuff was repaired using the double-row suture bridge technique. For suture bridge repair, 1 row of anchors was placed in the medial aspect of the footprint with or without tying, and transosseous repair of 
the torn cuff with a knotless anchor on the lateral aspect of the footprint was completed. If needed, additional procedures including capsular release, tenotomy, or tenodesis of the long head of the bicep tendon were performed. Acromioplasty was performed in all cases.

Patients were immobilized using a sling with an abduction pillow postoperatively, with the shoulder internally rotated at $30^{\circ}-40^{\circ}$ and abducted at $20^{\circ}$. Passive range of motion (ROM) exercises of the shoulder commenced on postoperative day 4 for small/medium tears and on day 22 for large/massive tears. For both tear types, active ROM and isotonic muscle strengthening exercises were allowed at postoperative week 6 and postoperative week 12 , respectively.

\section{Outcome measures}

The functional outcome measure was the UCLA score. ROM was assessed using a goniometer, and muscle strength was measured using a hand-held dynamometer (Micro FET2; Hoggan Health Industry, West Jordan, UT, USA). VAS scores were reported based on patients' subjective assessments.

Structural evaluation was performed using magnetic resonance imaging (MRI), according to a previous report [4]. A postoperative "intact tendon" was defined as types I-III in the Sugaya classification [9]. The tear length and width were evaluated as the coronal and sagittal oblique distance on T2-weighted images, respectively [10]. These measures were evaluated preoperatively and at 3 or 6 , and 12 months PO.

\section{Statistical analysis}

The JMP12 statistical software (SAS Institute, Cary, NC, USA) was used for statistical analyses. Because of the retrospective study design, the effect of HA injections on postoperative factors was evaluated after adjusting for confounding factors. Specifically, univariate analyses were performed to extract potential confounding factors with $p$ values less than 0.1 . Then, propensity scores were calculated with these potential confounding factors as explanatory variables. Finally, the propensity score was fitted to evaluate the injections at each follow-up period. Data are expressed as mean values with standard deviations. $P$ values $<0.05$ were considered to be statistically significant.

\section{Results}

UCLA scores of all patients significantly improved from 28.1 points preoperatively to 15.7 points 1 year PO $(p<$ 0.05) (Fig. 1a). The mean total UCLA scores were significantly different between the 2 groups preoperatively and 3 months PO ( $p>0.04$ and $p>0.03$, respectively) (Fig. 1b).

For functional outcomes, univariate analysis showed differences $(p<0.1)$ in the following items: UCLA score at 3 months PO, abduction strength at 4 months PO, and internal rotation (IR) strength 6 and 12 months PO. By contrast, there were no differences in structural outcomes between the groups (Table 1).

Next, propensity score analysis was performed to adjust for the confounding factors identified by univariate analysis. The results demonstrated that UCLA scores 3 months PO and IR strength 12 months PO were significantly better in the Injection group than in the noninjection group (Table 2). In the same manner, propensity score in sub-analysis in the injection group showed that co-use of local anesthetics did not affect the data, suggesting that the HA injections were effective.

\section{Discussion}

Our previous studies confirmed the various positive effects of HA injections on rotator cuff tears. In subacromial synovial fibroblasts, HA inhibited inflammatory

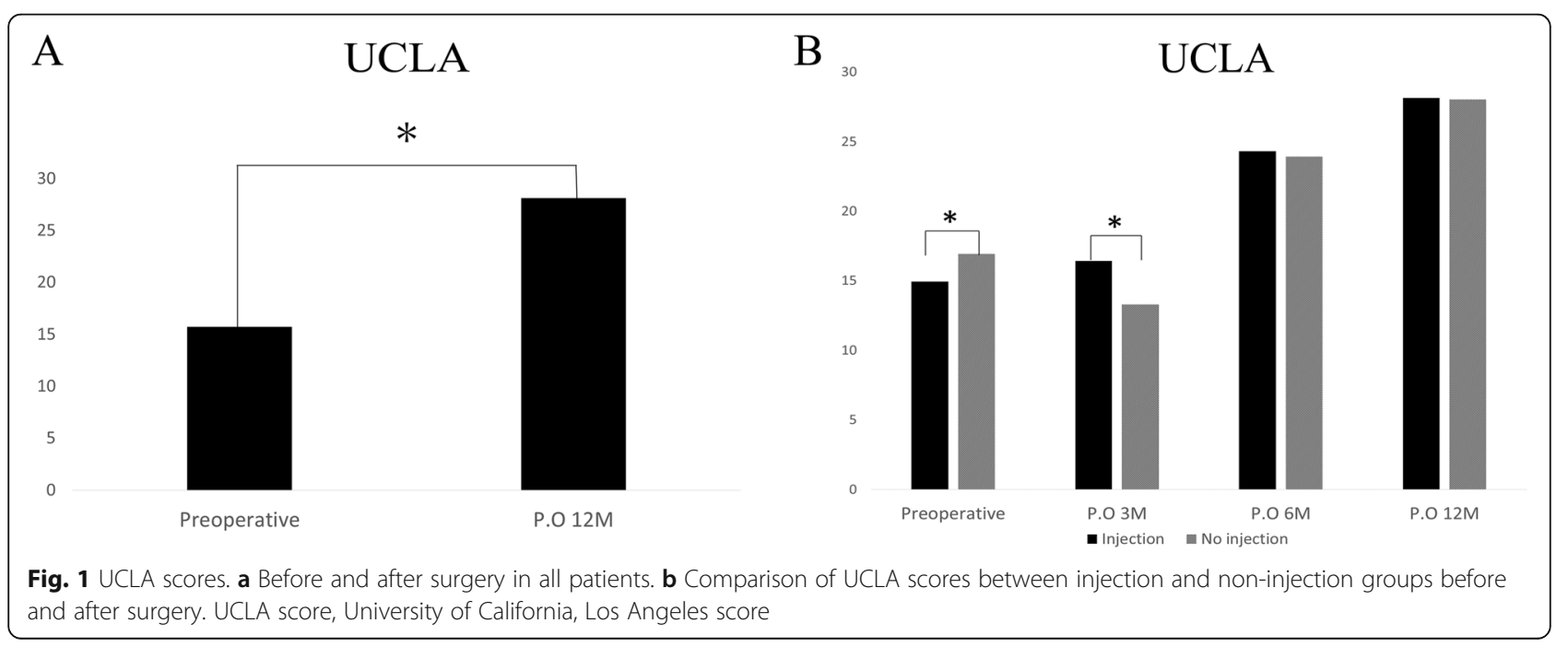


Table 1 Comparison between injection/non-injection groups by univariate analysis

\begin{tabular}{llll}
\hline Functional outcome & & & \\
\hline Univariate analysis & & & \\
\hline Variables & $\begin{array}{l}\text { Injection } \\
\text { group }\end{array}$ & $\begin{array}{l}\text { Non-injection } \\
\text { group }\end{array}$ & $p$ value \\
\hline Age (years) & 64.4 & 62.1 & 0.22
\end{tabular}

$\operatorname{Sex}(n)$

\begin{tabular}{llll}
\hline $\begin{array}{l}\text { Age (years) } \\
\text { Sex (n) }\end{array} \quad 64.4$ & 62.1 & 0.22 \\
$\quad$ Male & $32(55 \%)$ & $28(70 \%)$ & \\
$\quad$ Female & $26(44 \%)$ & $12(30 \%)$ & 0.13 \\
NSAID (n) & $37(63 \%)$ & $24(60 \%)$ & 0.70 \\
Hard work (n) & $21(38 \%)$ & $13(35 \%)$ & 0.71 \\
Diabetes mellitus (n) & $2(3 \%)$ & $5(12 \%)$ & $0.08^{\mathrm{a}}$ \\
Contracture (n) & $15(25 \%)$ & $7(17 \%)$ & 0.32 \\
Trauma (n) & $27(56 \%)$ & $13(37 \%)$ & $0.08^{\mathrm{a}}$ \\
Workmen's accidents (n) & $8(15 \%)$ & $5(14 \%)$ & 0.88 \\
Worker's compensation (n) & $8(15 \%)$ & $5(14 \%)$ & 0.88 \\
Follow-up period (months) & 8.4 & 8.9 & 0.81 \\
Preoperative & & & \\
VAS (rest) & 2.1 & 2.1 & 0.97 \\
VAS (motion) & 5.6 & 4.7 & 0.14 \\
VAS (night) & 4.5 & 3.6 & 0.17
\end{tabular}

Preoperative ROM

Elevation $\left(^{\circ}\right.$ )
Abduction $\left(^{\circ}\right.$ )
Internal rotation (level
of intervertebral body)
External rotation $\left(^{\circ}\right.$ )
Preoperative muscle strength
Elevation (relative ratio to
uninvolved side)
Abduction
Internal rotation
External rotation
UCLA score

Postoperative (PO) VAS

$\begin{array}{lll}\text { PO 3 M VAS (rest) } & 0.6 & 0.7 \\ \text { PO 3 M VAS (motion) } & 1.4 & 2.2 \\ \text { PO 3 M VAS (night) } & 0.8 & 1.4 \\ \text { PO 4 M VAS (rest) } & 0.4 & 0.7 \\ \text { PO 4 M VAS (motion) } & 2.1 & 2.7 \\ \text { PO 4 M VAS (night) } & 1.0 & 1.5 \\ \text { PO 6 M VAS (rest) } & 0.3 & 0.6 \\ \text { PO 6 M VAS (motion) } & 1.5 & 1.0 \\ \text { PO 6 M VAS (night) } & 0.7 & 0.9 \\ \text { PO 12 M VAS (rest) } & 0.3 & 0.4 \\ \text { PO 12 M VAS (motion) } & 1.1 & 1.0 \\ \text { PO 12 M VAS (night) } & 0.4 & 0.3\end{array}$

PO 12 M VAS (night)

Postoperative ROM

$$
\begin{aligned}
& \text { PO } 3 \mathrm{M} \text { elevation }\left({ }^{\circ}\right) \\
& \text { PO } 3 \mathrm{M} \text { abduction ( }{ }^{\circ} \text { ) }
\end{aligned}
$$

$\begin{array}{lll}107 & 112 & 0.52 \\ 99 & 106 & 0.44 \\ 5.2 & 5.5 & 0.62 \\ 48 & 45 & 0.51\end{array}$

Table 1 Comparison between injection/non-injection groups

\begin{tabular}{|c|c|c|c|}
\hline \multicolumn{4}{|l|}{ Functional outcome } \\
\hline \multicolumn{4}{|l|}{ Univariate analysis } \\
\hline Variables & $\begin{array}{l}\text { Injection } \\
\text { group }\end{array}$ & $\begin{array}{l}\text { Non-injection } \\
\text { group }\end{array}$ & $p$ value \\
\hline $\begin{array}{l}\text { PO } 3 \mathrm{M} \text { internal rotation (level } \\
\text { of intervertebral body) }\end{array}$ & 2.9 & 3.1 & 0.71 \\
\hline PO 3 M external rotation $\left({ }^{\circ}\right)$ & 20 & 17 & 0.48 \\
\hline PO 4 M elevation $\left({ }^{\circ}\right)$ & 114 & 119 & 0.44 \\
\hline PO $4 \mathrm{M}$ abduction $\left({ }^{\circ}\right.$ ) & 104 & 112 & 0.38 \\
\hline $\begin{array}{l}\text { PO } 4 \mathrm{M} \text { internal rotation (level } \\
\text { of intervertebral body) }\end{array}$ & 4.8 & 4.3 & 0.44 \\
\hline PO 4 M external rotation $\left({ }^{\circ}\right)$ & 28 & 28 & 0.93 \\
\hline PO $6 \mathrm{M}$ elevation $\left({ }^{\circ}\right)$ & 134 & 126 & 0.24 \\
\hline PO $6 \mathrm{M}$ abduction $\left({ }^{\circ}\right)$ & 133 & 127 & 0.39 \\
\hline $\begin{array}{l}\text { PO } 6 \mathrm{M} \text { internal rotation (level } \\
\text { of intervertebral body) }\end{array}$ & 6.6 & 5.5 & $0.08^{\mathrm{a}}$ \\
\hline PO $6 \mathrm{M}$ external rotation $\left({ }^{\circ}\right)$ & 36 & 34 & 0.57 \\
\hline PO $12 \mathrm{M}$ elevation $\left({ }^{\circ}\right)$ & 140 & 141 & 0.79 \\
\hline PO $12 \mathrm{M}$ abduction $\left({ }^{\circ}\right)$ & 142 & 143 & 0.88 \\
\hline $\begin{array}{l}\text { PO } 12 \mathrm{M} \text { internal rotation (level } \\
\text { of intervertebral body) }\end{array}$ & 8.1 & 7.9 & 0.80 \\
\hline PO $12 \mathrm{M}$ external rotation $\left({ }^{\circ}\right)$ & 38 & 38 & 0.87 \\
\hline \multicolumn{4}{|l|}{ Postoperative (PO) muscle strength } \\
\hline $\begin{array}{l}\text { PO } 3 \mathrm{M} \text { elevation (relative ratio } \\
\text { to uninvolved side) }\end{array}$ & 33 & 31 & 0.68 \\
\hline PO $3 \mathrm{M}$ abduction & 34 & 31 & 0.47 \\
\hline PO $3 \mathrm{M}$ internal rotation & 71 & 67 & 0.53 \\
\hline PO $3 \mathrm{M}$ external rotation & 58 & 57 & 0.95 \\
\hline $\begin{array}{l}\text { PO } 4 \mathrm{M} \text { elevation (relative ratio } \\
\text { to uninvolved side) }\end{array}$ & 55 & 48 & 0.25 \\
\hline PO $4 \mathrm{M}$ abduction & 61 & 49 & $0.06^{\mathrm{a}}$ \\
\hline PO $4 \mathrm{M}$ internal rotation & 82 & 80 & 0.70 \\
\hline PO 4 M external rotation & 77 & 74 & 0.82 \\
\hline $\begin{array}{l}\text { PO } 6 \mathrm{M} \text { elevation (relative ratio } \\
\text { to uninvolved side) }\end{array}$ & 70 & 59 & 0.10 \\
\hline PO $6 \mathrm{M}$ abduction & 71 & 64 & 0.39 \\
\hline PO $6 \mathrm{M}$ internal rotation & 90 & 93 & 0.58 \\
\hline PO $6 \mathrm{M}$ external rotation & 81 & 76 & 0.57 \\
\hline $\begin{array}{l}\text { PO } 12 \mathrm{M} \text { elevation (relative ratio } \\
\text { to uninvolved side) }\end{array}$ & 82 & 78 & 0.60 \\
\hline PO $12 \mathrm{M}$ abduction & 78 & 77 & 0.85 \\
\hline PO $12 \mathrm{M}$ internal rotation & 100 & 90 & $0.06^{\mathrm{a}}$ \\
\hline PO $12 \mathrm{M}$ external rotation & 83 & 87 & 0.65 \\
\hline \multicolumn{4}{|l|}{ Postoperative UCLA score } \\
\hline PO 3 M UCLA score & 16 & 13 & $0.03^{\mathrm{a}}$ \\
\hline PO 4 M UCLA score & 20 & 18 & 0.41 \\
\hline PO 6 M UCLA score & 24 & 23 & 0.74 \\
\hline PO 12 M UCLA score & 28 & 28 & 0.93 \\
\hline
\end{tabular}
by univariate analysis (Continued)

Data were evaluated by logistic analysis

NSAID non-steroidal anti-inflammatory drugs, ROM range of motion, VAS visual analog scale, UCLA score University of California at Los Angeles score ${ }^{a} p$ value $<0.1$ 
Table 2 Comparison between injection and non-injection groups after adjustment by propensity score analysis

\begin{tabular}{llll}
\hline & Injection & Non-injection & $p$ value \\
\hline UCLA score at 3 months & 16.4 & 13.3 & 0.03 \\
IR strength at 12 months & 1.0 & 0.9 & 0.02 \\
\hline
\end{tabular}

UCLA score University of California at Los Angeles score, IR internal rotation

cytokine production via the CD44 receptor; moreover, in glenohumeral synovial fibroblasts, HA inhibited adhesion-induced cytokine production via the CD44 receptor [11]. Honda et al. reported that HA may accelerate fibrocartilage formation in tendon-to-bone healing, with enhancement of this biomechanical property [12].

Several studies have reported the benefits of conservative therapy. Shibata et al. evaluated the effect of HA and steroid injections for rotator cuff tears after 4 weeks and 24 weeks, and found that pain and UCLA scores improved significantly after treatment with either injection [7]. In a randomized controlled trial, Blaine et al. reported that HA injections in the shoulder significantly alleviated pain, particularly at night [13]. Osti reported that intra-articular HA injections were effective in reducing pain and improving function in shoulders with rotator cuff tears, without severe adverse reactions [8]. Nevertheless, no studies have evaluated the effects of HA on clinical outcomes in patients with rotator cuff repairs. The present study compared the postoperative course in patients who underwent HA injections prior to surgery with those who did not received injections. We found that HA injections accelerated functional outcomes in terms of UCLA score 3 months PO and IR strength 12 months PO.

Despite having been worse preoperatively, UCLA scores improved postoperatively in the injection group. Many of the subjects had been referred to our hospital before surgery (of the 58 patients in the injection group, 25 received injections at our hospital and 33 at another hospital), and their clinical assessments at the start of treatment were unknown. However, the fact that preoperative UCLA scores were significantly lower in patients in the injection group suggested that their symptoms may have been relatively severe. Nevertheless, the fact that UCLA scores 3 months PO were significantly higher both before and after propensity score analysis correction provided supporting evidence for the effectiveness of HA injections.

Some patients in the injection group also received local anesthetic injections. Local anesthetics are cytotoxic to chondrocytes and tenocytes. Single-dose intraarticular administration of local anesthetics impedes chondrocyte metabolism and should be performed at low concentrations only for selected diagnostic purposes and painful joints [9]. Honda et al. reported that, in a rotator cuff tear model, local anesthetics led to apoptosis of tenocytes and delay of the granulation tissue maturation, causing biomechanical weakness of the enthesis involved [14]. Lee et al. reported that local anesthetic injections into the $S A B$ or shoulder joint immediately after ARCR significantly improved pain up to $24 \mathrm{~h}$ PO [15] Cook et al. compared SAB steroid or local anesthetic injections for rotator cuff-related shoulder pain and found that steroid injections improved pain significantly more effectively for up to 8 weeks; however, after this point, there was no difference between the 2 groups [16], and no negative effects have been reported in clinical practice. In a sub-analysis comparing HA injections alone with the combination of HA and local anesthetic injections, we found that there were no differences between the 2 in terms of either functional or imaging findings. This suggested that the combined use of local anesthetic had no effect on the efficacy of HA, including any toxic action.

Another common treatment for rotator cuff tears in addition to HA is steroid injections. Donohue et al. reported that patients who received a steroid injection in the SAB before undergoing ARCR had significantly better VAS scores, ASES shoulder scores, and constant scores 1 year PO compared with patients who did not receive these injections [16]. In a study of 12,000 patients, Desai et al. found that 2 or more steroid injections into the $\mathrm{SAB}$ before rotator cuff repair surgery significantly increased the risk of requiring further surgery within 2 years PO [5]. Basic research has also shown that the negative effects of steroids include inducing tenocyte apoptosis [17]. Reports on steroids are therefore divided; nevertheless, as far as we are aware, no adverse effects of HA injections have ever been reported. Lim et al. compared the efficacy of steroid injections with that of HA injections in the shoulder joint for shoulder periarthritis after 12 weeks, and found that both significantly improved pain, ASES shoulder score, and constant score, with no significant difference between the 2 [14]. Randomized controlled trials and further studies to investigate the effectiveness of HA and steroid injections are required in the future. Limitations of this study was retrospective, had a small sample size, was short-term, and the follow-up rate was low. Nevertheless, by compensating for these limitations using propensity scores, we successfully demonstrated the positive effects of HA on functional recovery after ARCR.

\section{Conclusions}

We used propensity score analysis to investigate the effect of $\mathrm{HA}$ injections into the $\mathrm{SAB}$ on postoperative function prior to ARCR. We found that preoperative HA injections significantly improved UCLA score 3 months PO and IR strength 12 months PO. 


\section{Abbreviations}

ARCR: Arthroscopic rotator cuff repair; NSAID: Nonsteroidal anti-inflammatory drug; SAB: Subacromial bursa; VAS: Visual analog scale; ASES: American shoulder and elbow surgeons; PO: Postoperatively; HA: Hyaluronic acid: UCLA: University of California, Los Angeles; ROM: Range of motion

\section{Acknowledgements}

Not applicable

\section{Authors' contributions}

YN collected, analyzed, and interpreted the data and wrote the paper. MG was involved in the study design and conception and in critically reviewing and revising the article content. YM, HN, and $\mathrm{HO}$ collected, analyzed, and interpreted the data. TO and NS were involved in critically reviewing and revising the article content. All authors read and approved the final manuscript.

\section{Funding}

This research received no specific grant from any funding agency in the public, commercial, or not-for-profit sectors.

\section{Availability of data and materials}

Data sharing is not applicable to this article as no datasets were generated or analyzed during the current study.

\section{Ethics approval and consent to participate}

This retrospective study was approved by the institutional review board of the Kurume University where this study was conducted (approval no. 18136). Due to the retrospective nature of the study, the requirement of patient consent was waived.

\section{Consent for publication}

Not applicable

\section{Competing interests}

The authors declare that they have no competing interests.

\section{Author details}

'Department of Orthopedic Surgery, Kurume University Hospital, 67 Asahi-machi, Kurume, Fukuoka 830-0011, Japan. ${ }^{2}$ Department of Orthopedic Surgery, Kurume University Medical Center, 155-1 Kokubu-machi, Kurume, Fukuoka 839-0863, Japan.

Received: 16 January 2020 Accepted: 20 May 2020

Published online: 03 June 2020

\section{References}

1. Rouhani A, Tabrizi A, Elmi A, et al. Effects of preoperative non-steroidal antiinflammatory drugs on pain mitigation and patients' shoulder performance following rotator cuff repair. Adv Pharm Bull. 2014;4:363.

2. Cancienne JM, Brockmeier SF, Carson EW, et al. Risk factors for infection after shoulder arthroscopy in a large Medicare population. Am J Sports Med. 2018:46:809-14.

3. Donohue NK, Prisco AR, Grindel SI. Pre-operative corticosteroid injections improve functional outcomes in patients undergoing arthroscopic repair of high-grade partial-thickness rotator cuff tears. Muscles Ligaments Tendons J. 2017;7:34

4. Nakamura $\mathrm{H}$, Gotoh M, Mitsui Y, et al. Factors affecting clinical outcome in patients with structural failure after arthroscopic rotator cuff repair. Arthroscopy. 2016:32:732-9.

5. Desai VS, Camp CL, Boddapati V, et al. Increasing numbers of shoulder corticosteroid injections within a year preoperatively may be associated with a higher rate of subsequent revision rotator cuff surgery. Arthroscopy. 2019;35:45-50

6. Lim TK, Koh KH, Shon MS, et al. Intra-articular injection of hyaluronate versus corticosteroid in adhesive capsulitis. Orthopedics. 2014;37:e860-5.

7. Shibata Y, Midorikawa K, Emoto G, et al. Clinical evaluation of sodium hyaluronate for the treatment of patients with rotator cuff tear. J Shoulder Elb Surg. 2001;10:209-16.

8. Osti L, Buda M, Del Buono A, et al. Clinical evidence in the treatment of rotator cuff tears with hyaluronic acid. Muscles Ligaments Tendons J. 2015; 5:270.
9. Sugaya H, Maeda K, Matsuki K, et al. Functional and structural outcome after arthroscopic full-thickness rotator cuff repair: single-row versus dual-row fixation. Arthroscopy. 2005;21:1307-16.

10. Davidson JJ, Burkhart SS, Richards DP, et al. Use of preoperative magnetic resonance imaging to predict rotator cuff tear pattern and method of repair. Arthroscopy. 2005;21:1428.e1-1428.e10.

11. Yamada T, Gotoh M, Nakama K, et al. Effects of hyaluronan on cell proliferation and mRNA expression of procollagens a1 (I) and a1 (III) in tendon-derived fibroblasts from patients with rotator cuff disease: an in vitro study. Am J Sports Med. 2007;35:1870-6.

12. Honda H, Gotoh M, Kanazawa T, et al. Hyaluronic acid accelerates tendonto-bone healing after rotator cuff repair. Am J Sports Med. 2017;45:3322-30.

13. Blaine T, Moskowitz R, Udell J, et al. Treatment of persistent shoulder pain with sodium hyaluronate: a randomized, controlled trial. A multicenter study. J Bone Joint Surg. 2008;90:970-9.

14. Honda $\mathrm{H}$, Gotoh M, Kanazawa T, et al. Effects of lidocaine on torn rotator cuff tendons. J Orthop Res. 2016;34:1620-7.

15. Lee HJ, Kim YS, Park I, et al. Administration of analgesics after rotator cuff repair: a prospective clinical trial comparing glenohumeral, subacromial, and a combination of glenohumeral and subacromial injections. J Shoulder Elb Surg. 2015;24:663-8.

16. Cook T, Lowe CM, Maybury M, et al. Are corticosteroid injections more beneficial than anaesthetic injections alone in the management of rotator cuff-related shoulder pain? A systematic review. Br I Sports Med. 2018;52: 497-504.

17. Nakamura H, Gotoh M, Kanazawa T, et al. Effects of corticosteroids and hyaluronic acid on torn rotator cuff tendons in vitro and in rats. J Orthop Res. 2015;33:1523-30.

\section{Publisher's Note}

Springer Nature remains neutral with regard to jurisdictional claims in published maps and institutional affiliations.

\section{Ready to submit your research? Choose BMC and benefit from:}

- fast, convenient online submission

- thorough peer review by experienced researchers in your field

- rapid publication on acceptance

- support for research data, including large and complex data types

- gold Open Access which fosters wider collaboration and increased citations

- maximum visibility for your research: over $100 \mathrm{M}$ website views per year

At BMC, research is always in progress.

Learn more biomedcentral.com/submissions 